would be more suitable.

An advantage of knot theory for explaining the methods of mathematics is that the problems can be stated simply, but solving them often requires a gamut of modern, but sometimes startlingly simple, ideas. Another feature is the use of analogy. For example, there is a way of composing knots and there is a notion of prime knots. So we have this extraordinary analogy between the way knots behave and the way numbers behave. But although there are an infinite number of prime knots, the proof of this is in no way analogous to the proof of the corresponding result for numbers.

Adams is an expert in knot theory, and this shows in the clarity and accuracy of his writing, and in the rich store of examples

\title{
A geographer on well-trodden ground
}

\section{PeterFrancis}

Volcanoes. By Alwyn Scarth. UCL Press/ Texas A\&M Univ. Press: 1994. Pp. 273. £40, $\$ 45$ (hbk); £14.95, \$19.95 (pbk).

THERE are many ways of knowing the world. In these politically correct times, scientists have learned that the perceptions of Earth held by other cultures may be as intrinsically valid as their own: science cannot be separated from the society in which it is carried out. Even within Western science, different disciplines have divergent perceptions of the same phenomena. Thus, whereas volcanologists passionately study volcanic ashes and lavas in order to seek an understanding of eruption mechanisms, geochemists view these merely as convenient samples from Earth's interior, and geophysicists ignore them entirely.

Most volcano books are written by authors with geological backgrounds. It is intriguing, therefore, to encounter one whose author explicitly states that he offers the perspective of a geographer. How might such a text differ from a conventional one? I expected an emphasis on the many ways in which volcanoes affect human society, not only directly through the obvious impact of eruptions, but also, for example, through their importance for agriculture and as sources of economic mineral deposits.

Alwyn Scarth has missed an opportunity here. Rather than opening a window on aspects of volcanoes generally skimped by his geological counterparts, he has preferred instead to revisit much ground already well trodden by them. In common with most other texts, he offers descriptions of the various kinds of volcano and volcanic eruptions, and several narrative accounts of eruptions. Although he brings a freshness to some rather routine and problems. A nice feature of the book is that, unusually for mathematics books topics are still the subject of current research, such as almost-alternating knots.

Many applications are given: there is a whole chapter entitled "Biology, Chemistry and Physics". A chapter on higherdimensional knots stirs the imagination, and there are problems of varying levels of difficulty for the reader to enjoy tackling. We are going to see much more of knot theory and its applications, and this book is an excellent place to start.

Ronald Brown is in the School of Mathematics, University of Wales, Bangor, Gwynedd LL57 1UT, UK. at the undergraduate level, some of the material, he is ill-prepared to take on geologists on their own turf, and his book contains some egregious errors and curious placements of emphasis. He has much to say, for example, about the scoria cones built up by minor strombolian eruptions, but very little about the huge eruptions that form calderas tens of kilometres in diameter, such as Long Valley in California.

Any introductory level text that aims to avoid technical language, as Scarth's does, is likely to contain simplifications that may make subject specialists wince. These are forgivable if they lead to enhanced understanding. But Scarth's well-intentioned simplifications sometimes mislead. Readers might conclude, for example, that Pompeii was destroyed in $\mathrm{AD} 79$ by the same kind of phenomenon that wrecked St Pierre (Martinique) in 1902, as Scarth uses the term nuée ardente (glowing cloud) for both. Although their consequences were similar, the two phenomena had very different origins: St Pierre lay on the margins of a glowing avalanche of dense rock cascading down the flanks of Mount Pelée, whereas Pompeii was devastated by pumice-laden hurricanes that swept down from the plinian eruption column rising above Mount Vesuvius.

Although highly readable, Scarth's treatment of eruptions is often idiosyncratic. He had the opportunity to present the first account in a popular book of the massive 1991 eruption of Mount Pinatubo, surely one of the most important this century. But his treatment, although admirably clear, runs to only half-a-dozen pages and is inexplicably sandwiched between an account of the minor eruption of Heimaey (Iceland) in 1973 and a lengthy description of the 1730-36 eruption on Lanzarote, Canary Islands.

Such reservations apart, the book has much to offer. Scarth has delved deeply into the histories of his favourite volcanoes, particularly those of the Azores and the Auvergne, and his crisply written accounts are full of fascinating details. The story that he unearthed of the evacuation of Lanzarote by the Spanish in 1731 is a real gem. It is an instructive example of the dilemmas authorities have to resolve when confronted by an erupting volcano, a starving, frightened population and all the economic and political disruption that an evacuation engenders. Scarth would have produced a better, more distinctive and more useful book if he had used his background as a geographer to provide us with more new perspectives on human issues such as these.

Peter Francis is in the Department of Earth Sciences, Open University, Milton Keynes MK7 6AA, UK.

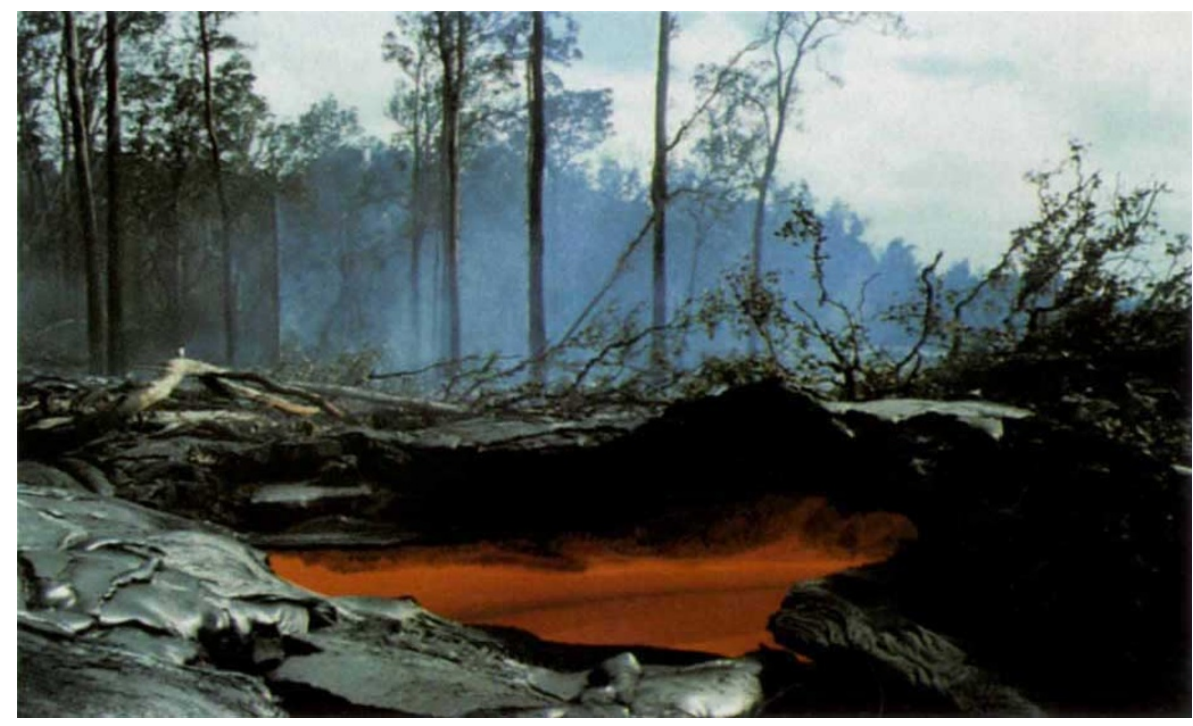

Lava flow, one of over 100 photographs by D. Weisel that appear in Fire on the Mountain: The Nature of Volcanoes, with text by C. Johnson. Chronicle Books, $\$ 29.95$ (hbk), $\$ 18.95$ (pbk). 